Research Article

\title{
Implication of Ceramide Kinase in Adipogenesis
}

\author{
Marta Ordoñez, Natalia Presa, Miguel Trueba, and Antonio Gomez-Muñoz \\ Department of Biochemistry and Molecular Biology, Faculty of Science and Technology, University of the Basque Country \\ (UPV/EHU), 48080 Bilbao, Spain
}

Correspondence should be addressed to Antonio Gomez-Muñoz; antonio.gomez@ehu.es

Received 26 April 2017; Accepted 21 June 2017; Published 20 July 2017

Academic Editor: Elisabetta Albi

Copyright @ 2017 Marta Ordoñez et al. This is an open access article distributed under the Creative Commons Attribution License, which permits unrestricted use, distribution, and reproduction in any medium, provided the original work is properly cited.

Ceramide kinase (CerK) plays a critical role in the regulation of cell growth and survival and has been implicated in proinflammatory responses. In this work, we demonstrate that CerK regulates adipocyte differentiation, a process associated with obesity, which causes chronic low-grade inflammation. CerK was upregulated during differentiation of 3T3-L1 preadipocytes into mature adipocytes. Noteworthy, knockdown of CerK using specific siRNA to silence the gene encoding this kinase resulted in substantial decrease of lipid droplet formation and potent depletion in the content of triacylglycerols in the adipocytes. Additionally, CerK knockdown caused blockade of leptin secretion, an adipokine that is crucial for regulation of energy balance in the organism and that is increased in the obese state. Moreover, CerK gene silencing decreased the expression of peroxisome proliferator-activated receptor gamma $(\operatorname{PPAR} \gamma)$, which is considered the master regulator of adipogenesis. It can be concluded that CerK is a novel regulator of adipogenesis, an action that may have potential implications in the development of obesity, and that targeting this kinase may be beneficial for treatment of obesity-associated diseases.

\section{Introduction}

Adipogenesis is the development of fully differentiated mature adipocytes from precursor cells. Apart from its role as triacylglycerol (TG) storage and energy homeostasis, adipose tissue is an endocrine organ that regulates crucial pathophysiological processes. Classical adipocyte-specific hormones include leptin [1], adiponectin [2], or resistin [3], but preadipocytes and mature adipocytes can also secrete numerous pro- and anti-inflammatory cytokines. Many of these so-called adipokines are involved in the regulation of glucose and lipid metabolism and are implicated in conditions of insulin resistance and obesity [4-6].

In recent years, sphingolipids and sphingolipidmetabolizing enzymes have emerged as key regulators of vital cellular functions including cell growth, differentiation, or cell death, and some of them are involved in inflammatory responses and inflammation-associated diseases such as cardiovascular diseases, cancer, and obesity. In particular, ceramides have been associated with insulin resistance leading to type II diabetes, and sphingosine and sphingosine kinases are altered in the obese state $[7,8]$. However, a putative role for ceramide kinase (CerK), the enzyme that phosphorylates ceramide to produce ceramide 1-phosphate (C1P), in adipogenesis has remained largely unknown.

The present study was undertaken to evaluate whether CerK was implicated in adipocyte differentiation, which is a target for therapy of obesity-related diseases.

\section{Materials and Methods}

2.1. Materials. The culture medium Dulbecco's modified Eagle's medium (DMEM) used in all the experiments was purchased from Lonza. The triacylglycerol assay kit was purchased from Abnova. NBD-ceramide (NBD-N-hexanoyl-D-erythro-sphingosine) was from Cayman Chemicals. Dexamethasone, rosiglitazone, insulin, 3-isobutyl-1-methylxanthine (IBMX), and the Oil Red O dye were obtained from Sigma-Aldrich. Nitrocellulose membranes, protein markers, and BCA assay reagents were purchased from Bio-Rad. Fetal bovine serum (FBS) and newborn calf serum (NCS) were from GIBCO. The ELISA kit for determination of leptin was purchased from Peprotech. The PPAR $\gamma$ antibody was supplied by Cell Signaling. The GAPDH antibody, 
nontargeting (negative) siRNA, and ceramide kinase (CerK) siRNA were purchased from Santa Cruz Biotechnology. The CerK antibody was from Calbiochem or Abgent. The rest of chemicals and reagents used in this work were of the highest grade available.

2.2. Cell Culture. The 3T3-L1 cell line is a fibroblast cell line purchased from the American Type Culture Collection (ATCC) (Manassas, VA, USA) and was cultured following the manufacturer's indications. Cells were grown in $175 \mathrm{~cm}^{2}$ flasks in DMEM supplemented with $10 \%$ heat-inactivated newborn calf serum (NCS), $50 \mathrm{mg} / \mathrm{l}$ gentamicin, $200 \mu \mathrm{M}$ L-glutamine, and $4.5 \mathrm{~g} / \mathrm{l}$ glucose. Cells were incubated in a humidified $5 \% \mathrm{CO}_{2}$ incubator at $37^{\circ} \mathrm{C}$ and subcultured every 3-4 days. Cells were used in experiments at about 80-100\% confluence.

2.3. 3T3-L1 Preadipocyte Differentiation Protocol. 3T3-L1 preadipocytes were seeded in 6 -well plates at $1.2 \times 10^{5}$ cells/ well or in 24 -well plates at $6 \times 10^{4}$ cells/well or in 96-well plates at $9 \times 10^{3}$ cells/well depending on the kind of experiment to be performed. The cells were then cultured in DMEM supplemented with 10\% NCS until they were about 90-100\% confluent. The cells were then further incubated for 2 days. The preadipocytes were treated with adipogenic induction medium, which is a medium consisting of DMEM $10 \%$ FBS supplemented with an adipogenic cocktail containing $0.5 \mathrm{mM}$ IBMX, $1 \mu \mathrm{g} / \mathrm{ml}$ insulin, $0.25 \mu \mathrm{M}$ dexamethasone, and $2 \mu \mathrm{M}$ rosiglitazone. Two days later, the medium was removed and cells were incubated further in maintenance medium (DMEM 10\% FBS $+1 \mu \mathrm{g} / \mathrm{ml}$ insulin) for two additional days. The cells were then fed every two days with DMEM supplemented with $10 \%$ FBS and $1 \mu \mathrm{g} / \mathrm{ml}$ insulin.

2.4. Western Blotting. Preadipocytes were harvested and lysed in ice-cold homogenization buffer to analyze proteins by Western blotting, essentially as described in [9]. Specifically, 3 T3-L1 cells were seeded at $1.2 \times 10^{5}$ cells/well in 6 -well plates and were differentiated in the presence or in the absence of CerK siRNA, following the above described preadipocyte differentiation protocol (Section 2.3). Western blotting was performed as detailed in [10]. About 20-40 $\mu \mathrm{g}$ of protein from each sample was loaded and separated by sodium dodecyl sulfate polyacrylamide gel electrophoresis (SDS-PAGE), using 12\% separating gels. Proteins were transferred onto nitrocellulose membranes and blocked with 5\% skim milk for $1 \mathrm{~h}$ in Tris-buffered saline (TBS) containing $0.1 \%$ Tween 20 and then incubated overnight with the primary antibody in TBS- $0.1 \%$ Tween 20 at $4^{\circ} \mathrm{C}$. After three washes with TBS-0.1\% Tween 20, membranes were incubated with horseradish peroxidase-conjugated secondary antibody at 1:4000 dilution for $1 \mathrm{~h}$. Bands were visualized by enhanced chemiluminescence and exposed films were analyzed with an ImageJ software.

2.5. Oil Red O Staining Protocol. 3T3-L1 preadipocytes were seeded at $6 \times 10^{4}$ cells/well in 24-well plates and differentiated in the absence or in the presence of CerK siRNA, following the above described preadipocyte differentiation protocol (Section 2.3). Intracellular lipid accumulation was determined using a solution of Oil Red O. Briefly, cells were washed with PBS and fixed in 3.8\% formaldehyde for $10 \mathrm{~min}$. They were then washed and stained with a solution containing Oil Red $\mathrm{O}(3 \mathrm{mg} / \mathrm{ml})$ and isopropanol in water $(60 / 40, v / v)$ for $20 \mathrm{~min}$ at room temperature. Stained cells were washed twice with water and photographed with a Nikon Eclipse TS100 microscope. To assess the degree of differentiation, $200 \mu$ l isopropanol was added and incubated for $30 \mathrm{~min}$ in a plate shaker. Then, $50 \mu \mathrm{l}$ of Oil Red O extracted dye was transferred into 96-well plates and quantified by reading the absorbance at a wavelength of $510 \mathrm{~nm}$. The dye extracted from the empty wells represented the nonspecific binding of the dye to the plate. The nonspecific binding value was subtracted from the absorbance of each experimental condition to obtain accurate measurements of specific staining.

2.6. Triacylglycerol Measurement. 3T3-L1 preadipocytes were seeded at $9 \times 10^{3}$ cells/well in 96-well plates and differentiated in the absence or in the presence of CerK siRNA, following the above described preadipocyte differentiation protocol (Section 2.3). For determination of the triglyceride (TG) content in cells, the manufacturer's instructions were followed. Briefly, cells were washed with PBS and $100 \mu \mathrm{l}$ of the lipid extraction solution was added to each well. Then, the plates were incubated in a heating block at $90-100^{\circ} \mathrm{C}$ for $30 \mathrm{~min}$. After this time, $50 \mu \mathrm{l} /$ well of standard dilutions of TG or 5-50 $\mu \mathrm{l}$ of the lipid extracts were transferred into 96-well plates. Assay buffer was added where necessary to bring the volume up to $50 \mu \mathrm{l}$ in all wells. Then, $2 \mu \mathrm{l}$ of lipase solution was added to each well containing either sample or standard, and the whole plate was incubated for $10 \mathrm{~min}$ at room temperature. Subsequently, $50 \mu \mathrm{l}$ of the reaction mixture $(46 \mu \mathrm{l}$ adipogenesis assay buffer $+2 \mu \mathrm{l}$ probe $+2 \mu \mathrm{l}$ enzyme mix) was added to each well and incubated at $37^{\circ} \mathrm{C}$ for $30 \mathrm{~min}$ in the dark. The absorbance was read at $570 \mathrm{~nm}$ in a plate reader. The protein concentration of the lipid extracts was determined using a commercial kit containing bicinchonic acid (BCA), from Bio-Rad, and the values were used as internal controls to normalize the lipid concentration in the samples.

2.7. Treatment of Cells with siRNA. 3T3-L1 preadipocytes were seeded in $100 \mathrm{~mm}$ diameter dishes at $5 \times 10^{5}$ cells/plate and incubated for $48 \mathrm{~h}$ as indicated in Section 2.2. The cells were then transferred into electroporation cuvettes and $20 \mathrm{pmol} / \mathrm{ml}$ of siRNA (from a $10 \mu \mathrm{M}$ siRNA stock solution) was added. Cells were then electroporated $(1000 \mathrm{v}, 30 \mu \mathrm{S})$ using an Electro Square Porator (ECM 830). Electroporated cells were then seeded at $2 \times 10^{4}$ cells/well in 96-well plates or $1.2 \times 10^{5}$ cells/well in 24 -well plates or $5 \times 10^{5}$ cells/well in 6-well plates, depending on the particular experiment to be performed, and incubated in differentiation medium, as required. The silencing efficiency of the siRNA treatment was analyzed by Western blotting and by measuring CerK activity.

2.8. Determination of CerK Activity. CerK activity was essentially determined as described by Don and Rosen [11]. 


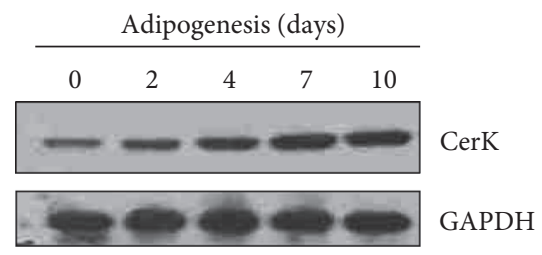

(a)

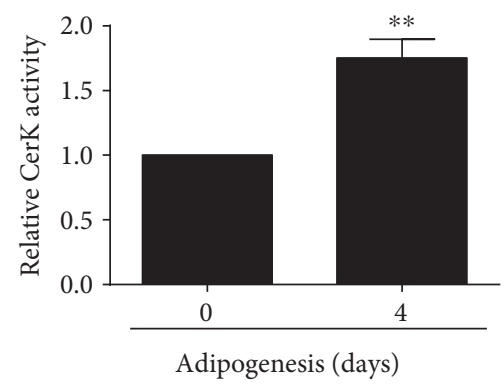

(c)

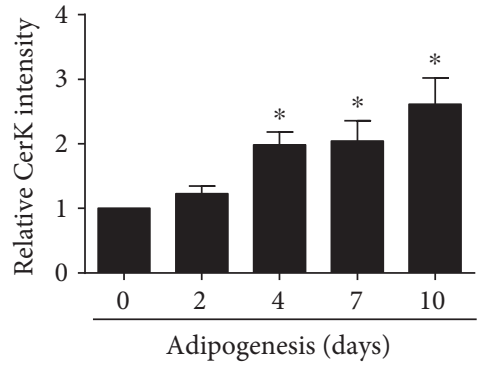

(b)

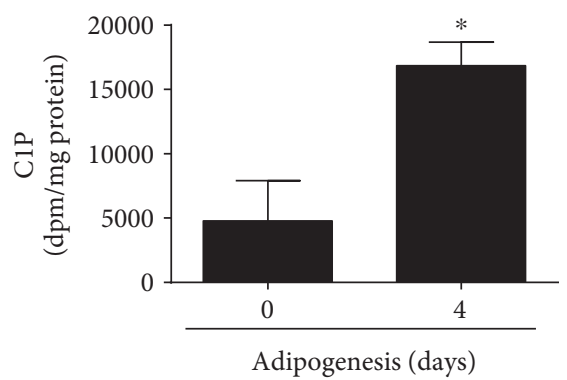

(d)

FIGURE 1: CerK is upregulated during adipogenesis. Cells were seeded in 6-well plates $\left(1.2 \times 10^{5}\right.$ cells/well), and they were differentiated as described in Materials and Methods. (a) CerK was detected by Western blotting using a specific antibody. Equal loading of protein was assessed with an antibody against GAPDH. Similar results were obtained in each of 4 replicate experiments. (b) Results of the scanning densitometry of exposed film. Data are expressed as arbitrary units of intensity relative to GAPDH and are the mean \pm SEM of 4 independent experiments $\left({ }^{*} p<0.05\right)$. (c) CerK activity was determined as described in Materials and Methods. Data are expressed as the mean \pm SEM of 5 independent experiments $\left({ }^{* *} p<0.01\right)$. (d) C1P levels were determined as described in Materials and Methods. Data are expressed as the mean \pm SEM of four independent determinations $\left({ }^{*} P<0.05\right)$.

3T3-L1 cells were seeded in 6 -well plates at $1.2 \times 10^{5}$ cells/ well and differentiated in the absence or in the presence of CerK siRNA, following the preadipocyte differentiation protocol described above (Section 2.3). Cell lysates (50-100 $\mu \mathrm{g}$ of protein) were mixed with reaction buffer $(100 \mu \mathrm{l}, 20 \mathrm{mM}$ Hepes (pH 7.4), $10 \mathrm{mM} \mathrm{KCl}, 15 \mathrm{mM} \mathrm{MgCl} 2,15 \mathrm{mM} \mathrm{CaCl}_{2}$, $10 \%$ glycerol, $1 \mathrm{mM}$ DTT, and $1 \mathrm{mM}$ ATP) containing $10 \mu \mathrm{M}$ of NBD-C6-ceramide (N-hexanoyl-D-erythro-sphingosine). The reactions were allowed to proceed for $30 \mathrm{~min}$ in the dark. Then, $250 \mu \mathrm{l}$ aliquots of chloroform : methanol $(2: 1)$ were added to terminate the reactions. Samples were then centrifuged at $280,800 \mathrm{~g}$ for $30 \mathrm{~s}$, and $100 \mu \mathrm{l}$ aliquots of the upper aqueous phase were transferred into 96-well plates. Subsequently, $100 \mu \mathrm{l}$ aliquots of dimethylformamide (DMF) were added before reading the NBD fluorescence in an appropriate plate reader. Fluorescence was quantified with a $495 \mathrm{~nm}$ excitation filter and a $520 \mathrm{~nm}$ emission filter with a Synergy HT (Biotek) plate reader equipped with Gen5 software.

2.9. Determination of $\mathrm{C} 1 \mathrm{P}$ Levels. $\mathrm{C} 1 \mathrm{P}$ was analyzed by labeling the cells with $\left[{ }^{3} \mathrm{H}\right]$ palmitate essentially as described in [12], followed by separation of C1P by thin-layer chromatography [13]. Specifically, 3T3-L1 preadipocytes were seeded in 6-well plates at $1.2 \times 10^{5}$ cells/well and incubated in differentiation medium for four days, following the above described preadipocyte differentiation protocol (Section 2.3). $\left[{ }^{3} \mathrm{H}\right]$ Palmitate $(2 \mu \mathrm{Ci} / \mathrm{ml})$ was present in the culture medium for the last $24 \mathrm{~h}$. The radioactive medium was then removed and the cells were washed twice with nonradioactive DMEM and collected for determination of $\left[{ }^{3} \mathrm{H}\right] \mathrm{C} 1 \mathrm{P}$ formation. To this purpose, the cells were scraped in $0.5 \mathrm{ml}$ of methanol, and the wells were washed with an equal volume of methanol. The two $0.5 \mathrm{ml}$ methanol samples were combined and mixed with $0.5 \mathrm{ml}$ of chloroform. The lipids were extracted by separation of phases with an additional volume of $0.5 \mathrm{ml}$ of chloroform to which $0.9 \mathrm{ml}$ of a solution containing $2 \mathrm{M}$ $\mathrm{KCl}$ and $0.2 \mathrm{M} \mathrm{HCl}$ was added. The chloroform phases were isolated and dried down under a stream of nitrogen. Subsequently, glycerophospholipids were eliminated by mild alkaline hydrolysis incubating the samples in $0.5 \mathrm{M}$ methanolic $\mathrm{KOH}$ at $37^{\circ} \mathrm{C}$ for $30 \mathrm{~min}$ with continuous shaking. After the hydrolysis, lipids were re-extracted by separation of phases as indicated above. The lipid extracts were dissolved in $50 \mu \mathrm{l}$ of chloroform containing $50 \mu \mathrm{g}$ of cold C1P as carrier and were applied directly to aluminum- or glass-backed silica gel 60 plates to separate the lipids. The silica gel plates were developed sequentially with three different solvent systems. Solvent 1 consisted of chloroform/methanol/ $/ \mathrm{NH}_{4} \mathrm{OH}$ $(65: 35: 7.5, v / v / v)$ and was run up to $11.5 \mathrm{~cm}$ from the origin, which was set up at $1.5 \mathrm{~cm}$ from the bottom of the plate. Solvent 2 contained chloroform/methanol/acetic acid $(9: 1: 1$, $v / v / v)$ and was run up to the top of the plate. Solvent 3 consisted of 1-butanol/acetic acid/water $(3: 1: 1, v / v / v)$ and was run up to $14 \mathrm{~cm}$ from the origin. The plates were dried in a fume hood after each solvent run before they were 


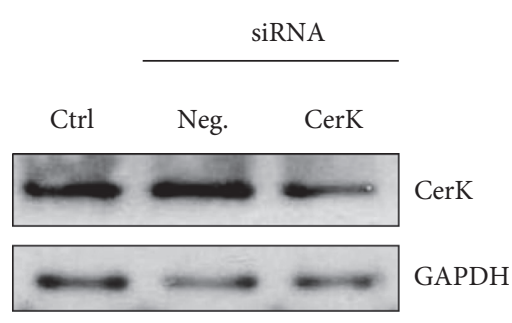

(a)

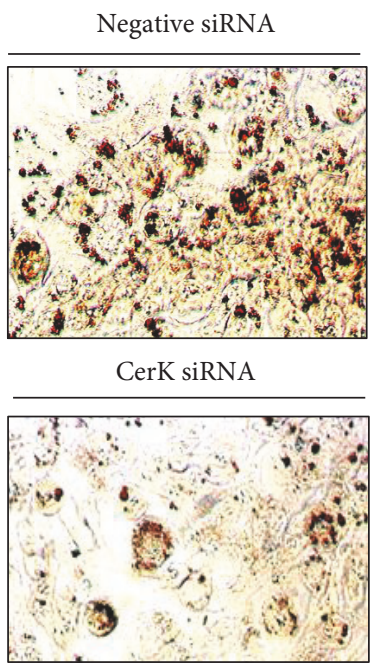

(c)

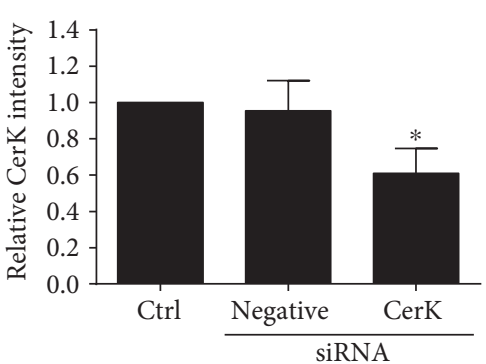

(b)

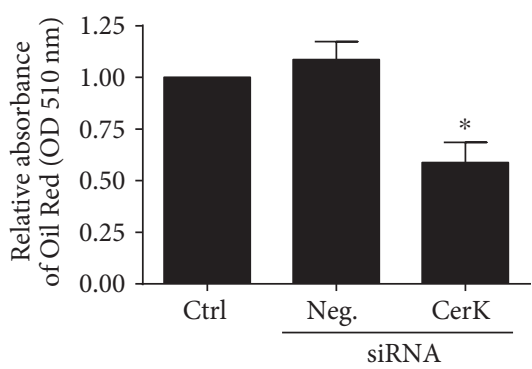

(d)

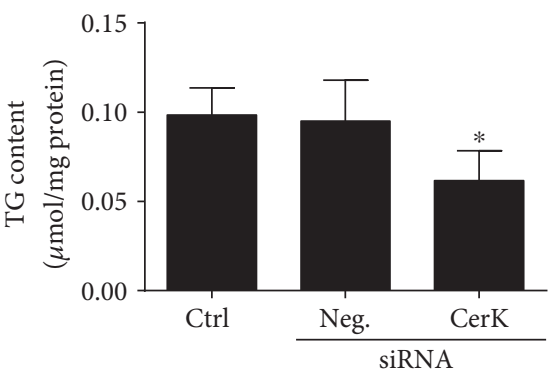

(e)

Figure 2: CerK downregulation leads to decreased lipid droplet formation and depletion of TG content in 3T3-L1 cells. The preadipocytes were seeded in $100 \mathrm{~mm}$ diameter dishes at $5 \times 10^{5}$ cells/plate and incubated for $48 \mathrm{~h}$ as indicated in Section 2.2 . They were then electroporated in the absence of siRNA (ctrl) or in the presence of negative (scrambled) siRNA (Neg siRNA) or Cerk siRNA, as indicated in Materials and Methods, and were then differentiated up to day 4. (a) CerK knockdown using specific siRNA was confirmed by immunoblotting. Equal loading of protein was assessed with an antibody against GAPDH. Similar results were obtained in each of 3 replicate experiments. (b) Results of the scanning densitometry of exposed film. Data are expressed as arbitrary units of intensity relative to GAPDH and are the mean \pm SEM of 3 independent experiments $\left({ }^{*} p<0.05\right)$. (c) Light micrographs of adipocytes stained with Oil Red $\mathrm{O}$ at day 4 after differentiation are shown. Pictures were taken with a motorized Nikon Eclipse TS100 microscope at 20x magnification. (d) Cells were stained with Oil Red $\mathrm{O}$, and lipid droplets were quantified at day 4 after differentiation as indicated in Materials and Methods. Data are expressed as the mean \pm SEM of 5 independent experiments performed in triplicate $\left({ }^{*} p<0.05\right)$. (e) Triacylglycerol (TG) content of cells was measured at day 4 after differentiation as described in Materials and Methods. Results are the mean \pm SEM of 3 independent experiments performed in triplicate $\left({ }^{*} p<0.05\right)$.

developed in the next corresponding solvent. C1P was identified after staining the plates with iodine vapor by comparison with authentic standards. Radioactivity was quantified by scraping the $\mathrm{C} 1 \mathrm{P}$ spots from the silica plates by liquid scintillation counting.

2.10. Statistical Analyses. Results are expressed as means \pm SEM of three to six independent experiments performed in duplicate unless indicated otherwise. Statistical analyses were performed using the two-tailed, paired Student's $t$-test, where $p<0.05$ was considered to be significant (GraphPad Prism Software, San Diego, CA) [10].

\section{Results}

3.1. CerK Is Upregulated during Adipogenesis in 3T3-L1 Cells. The implication of CerK in adipogenesis was tested using 3T3-L1 mouse preadipocytes. We observed that the protein level of CerK was upregulated under adipogenic differentiation conditions when the cells were incubated up to 10 days in differentiation cell culture medium (Figures 1(a) and 1(b)). We also observed that CerK activity increased significantly under differentiation conditions (Figure 1(c)) and that C1P levels were elevated by about 3.5-fold when the cells were preincubated with $2 \mu \mathrm{Ci} / \mathrm{ml}$ of $\left[{ }^{3} \mathrm{H}\right]$ palmitate 


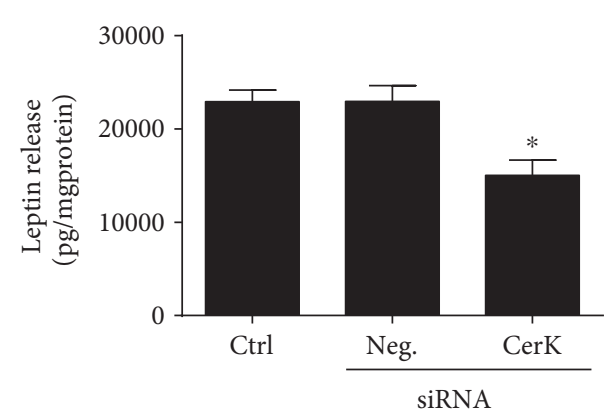

(a)

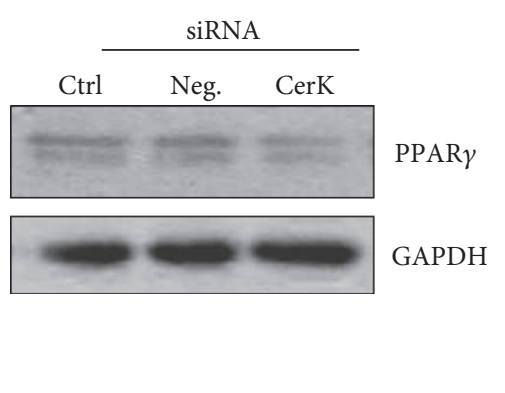

(b)

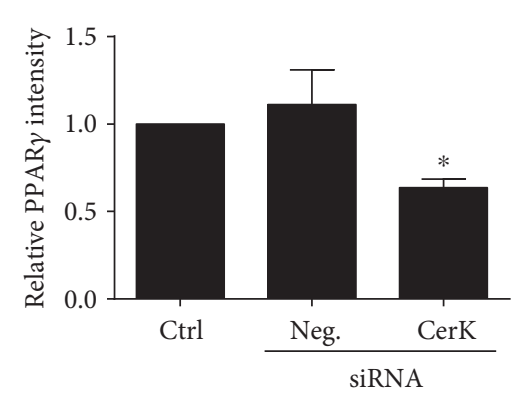

(c)

FIGURE 3: CERK downregulation leads to inhibition of leptin secretion and inhibition of PPAR- $\gamma$ expression. The preadipocytes were seeded in $100 \mathrm{~mm}$ diameter dishes at $5 \times 10^{5}$ cells/plate and incubated for $48 \mathrm{~h}$ as indicated in Section 2.2. The cells were then electroporated in the absence of siRNA (ctrl) or in the presence of negative (scrambled) siRNA (Neg siRNA) or Cerk siRNA, as indicated in Materials and Methods. (a) Leptin concentration in supernatants was measured at day 4 after differentiation using an ELISA kit, as described in Materials and Methods. Results are the mean \pm SEM of 4 independent experiments performed in duplicate $\left({ }^{*} p<0.05\right)$. (b) PPAR $\gamma$ expression was detected by Western blotting using a specific antibody. Equal loading of protein was assessed with an antibody against GAPDH. Similar results were obtained in each of 5 replicate experiments. (c) Results of scanning densitometry of the exposed film. Data are expressed as arbitrary units of intensity relative to GAPDH and are the mean \pm SEM of 5 independent experiments $\left({ }^{*} p<0.05\right)$.

to label cell lipids, including sphingolipids, under the same conditions (Figure 1(d)).

3.2. CerK Contributes to Adipogenesis in 3T3-L1 Cells. The role of CerK in adipogenesis was investigated by transfecting siRNA targeting CerK into 3T3-L1 preadipocytes to silence the gene encoding this kinase. The knockdown of CerK by siRNA treatment was confirmed by immunoblotting (Figures 2(a) and 2(b)). Surprisingly, cells deficient in CerK resulted in reduced adipogenic differentiation and decreased formation of lipid droplets compared to control cells. Lipid droplets were detected by Oil Red $\mathrm{O}$ staining at 4 days after induction of adipogenesis (Figures 2(c) and 2(d)). In addition, the content of TG was substantially decreased in siRNA CerK-treated cells compared to control cells (Figure 2(e)).

3.3. CerK Deficiency Results in Reduced Leptin Release and Inhibition of PPAR $\gamma$ Expression. Leptin is the central regulator of energy balance and appetite in the organism. It is produced only after the induction of adipocyte differentiation, and as such, it has been used as a late marker of adipogenesis [14]. In addition, leptin exerts proinflammatory actions in the obese state [14]. We show in this work that CerK knockdown with specific CerK siRNA significantly decreases leptin release by the adipocytes during cell differentiation (Figure 3(a)), thereby reinforcing the notion that CerK is a relevant factor in adipogenesis.

Many proadipogenic transcription factors have been characterized, but no one is as critical as the peroxisome proliferator-activated receptor gamma $(\operatorname{PPAR} \gamma)$, which is considered the master regulator of adipocyte differentiation [4]. In fact, the majority of factors controlling adipocyte differentiation also affect the activity of this crucial regulator of adipogenesis [15]. Noteworthy, we show in this work that CerK knockdown with specific CerK siRNA significantly decreases PPAR $\gamma$ protein levels in the adipocytes during cell differentiation (Figures 3(b) and 3(c)), suggesting that the expression of this transcription factor is under regulation by CerK.

\section{Discussion}

In the present study, we have investigated the role of CerK in adipogenesis using 3T3-L1 preadipocytes as cellular model. CerK expression was increased during adipogenic differentiation, and CerK knockdown resulted in impaired adipogenesis as determined by the reduction of lipid droplet formation and the TG content of cells. The latter results are consistent with recent work showing that CerK deficiency improves diet-induced obesity and insulin resistance [16]. CerK deficiency resulted in significant decrease of leptin secretion, an adipokine that is increased in the obese state $[4,14]$. Leptin has proinflammatory properties and can induce the secretion of inflammatory cytokines such as tumor necrosis factor-alpha (TNF- $\alpha$ ), interleukin-6 (IL-6), or IL-12 $[17,18]$. In turn, proinflammatory TNF- $\alpha$ and IL- $1 \beta$ can upregulate the expression of leptin mRNA in the adipose tissue, leading to a loop that potentiates inflammation [18, 19]. Therefore, the reduction of leptin levels by downregulation of CerK would attenuate the proinflammatory effects of this adipokine. This is an important aspect in the context of obesity, which is a low-grade inflammatory condition. The involvement of CerK in inflammation was first suggested by Chalfant and coworkers who showed that CerK mediates IL- $1 \beta$-induced arachidonic acid release, which is the precursor of inflammatory eicosanoids [20]. Subsequent studies by the same group demonstrated that $\mathrm{C} 1 \mathrm{P}$, the product of CerK, was a direct activator of cytosolic phospholipase $A_{2}$ [21], a major enzyme responsible for the regulation of arachidonic acid release in mammalian cells, and that eicosanoid levels were lower in primary mouse embryonic fibroblasts isolated from CerK knockout mice [22]. Moreover, depleting CerK activity using either specific siRNA to silence the gene encoding this kinase or the 
pharmacological inhibitor NVP-231 completely blocked eicosanoid biosynthesis [23]. Additionally, we show here that CerK-deficient cells cause potent reduction in the protein levels of the crucial adipogenesis marker PPAR $\gamma$, which is both necessary and sufficient for adipocyte differentiation [24], thereby suggesting that the loss of CerK might be detrimental for optimal adipogenic differentiation.

The above results suggest that CerK activity might regulate adipocyte differentiation by targeting the expression of adipogenic genes. In addition, the increased expression of CerK and C1P formation during adipogenesis are consistent with the substantial reduction of ceramide levels during differentiation of 3T3-L1 preadipocytes [25], as CerK produces C1P from ceramides. Although this may be a major mechanism for controlling adipogenesis, further investigation is required to identify the signaling pathways involved in this process and to clearly understand the molecular mechanisms that are implicated in CerK-mediated adipogenesis.

In summary, we have identified CerK as a novel regulator of adipogenesis. The increased levels of CerK expression during adipocyte differentiation point to a putative role of this kinase in the onset or development of obesity. In fact, obesity is an inflammatory condition that is primarily attributed to expansion and inflammation of adipose tissue [26]. It can be concluded that CerK is a new regulator of adipogenesis with potential implications in obesity and that targeting CerK may prove useful in the treatment of obesity-associated diseases.

\section{Abbreviations}

BCA: Bicinchonic acid

C1P: $\quad$ Ceramide 1-phosphate

CerK: Ceramide kinase

DMEM: Dulbecco's modified Eagle's culture medium

FBS: $\quad$ Fetal bovine serum

IBMX: 3-Isobutyl-1-methyxanthine

PBS: $\quad$ Phosphate-buffered saline

PPAR $\gamma$ : Peroxisome proliferator-activated receptor gamma TG: Triacylglycerol.

\section{Conflicts of Interest}

The authors declare that they have no conflicts of interest.

\section{Acknowledgments}

The present work was supported by the "Departamento de Educación, Universidades e Investigación del Gobierno Vasco," Basque Country, Spain (Grant IT1106-16) and the "Ministerio de Economía y Competitividad," Madrid, Spain (Grant SAF2016-79695-R). Marta Ordoñez received a fellowship from the University of the Basque Country, and Natalia Presa is the recipient of a fellowship from the Basque Government. The authors are grateful to "Unidad de Formación e Investigación (UFI) 11/20 (UPV/EHU)" for the technical support.

\section{References}

[1] Y. Zhang, R. Proenca, M. Maffei, M. Barone, L. Leopold, and J. M. Friedman, "Positional cloning of the mouse obese gene and its human homologue," Nature, vol. 372, pp. 425432, 1994.

[2] P. E. Scherer, S. Williams, M. Fogliano, G. Baldini, and H. F. Lodish, "A novel serum protein similar to $\mathrm{C} 1 \mathrm{q}$, produced exclusively in adipocytes," The Journal of Biological Chemistry, vol. 270, pp. 26746-26749, 1995.

[3] C. M. Steppan, S. T. Bailey, S. Bhat et al., "The hormone resistin links obesity to diabetes," Nature, vol. 409, pp. 307$312,2001$.

[4] K. Sarjeant and J. M. Stephens, "Adipogenesis," Cold Spring Harbor Perspectives in Biology, vol. 4, article a008417, 2012.

[5] J. Ye, "Emerging role of adipose tissue hypoxia in obesity and insulin resistance," International Journal of Obesity, vol. 33, pp. 54-66, 2009.

[6] K. Meijer, M. d. Vries, S. Al-Lahham et al., "Human primary adipocytes exhibit immune cell function: adipocytes prime inflammation independent of macrophages," PloS One, vol. 6, article e17154, 2011.

[7] P. J. Larsen and N. Tennagels, "On ceramides, other sphingolipids and impaired glucose homeostasis," Molecular Metabolism, vol. 3, pp. 252-260, 2014.

[8] M. H. Moon, J. K. Jeong, and S. Y. Park, “Activation of S1P2 receptor, a possible mechanism of inhibition of adipogenic differentiation by sphingosine 1-phosphate," Molecular Medicine Reports, vol. 11, pp. 1031-1036, 2015.

[9] J. A. Hamilton, D. Myers, W. Jessup et al., "Oxidized LDL can induce macrophage survival, DNA synthesis, and enhanced proliferative response to CSF-1 and GM-CSF," Arteriosclerosis, Thrombosis, and Vascular Biology, vol. 19, pp. 98-105, 1999.

[10] M. Ordonez, I. G. Rivera, N. Presa, and A. Gomez-Munoz, "Implication of matrix metalloproteinases 2 and 9 in ceramide 1-phosphate-stimulated macrophage migration," Cellular Signalling, vol. 28, pp. 1066-1074, 2016.

[11] A. S. Don and H. Rosen, "A fluorescent plate reader assay for ceramide kinase," Analytical Biochemistry, vol. 375, pp. 265$271,2008$.

[12] M. H. Granado, P. Gangoiti, A. Ouro, L. Arana, and A. Gomez-Munoz, "Ceramide 1-phosphate inhibits serine palmitoyltransferase and blocks apoptosis in alveolar macrophages," Biochimica et Biophysica Acta, vol. 1791, pp. 263-272, 2009.

[13] A. Gomez-Munoz, P. A. Duffy, A. Martin et al., "Short-chain ceramide-1-phosphates are novel stimulators of DNA synthesis and cell division: antagonism by cell-permeable ceramides," Molecular Pharmacology, vol. 47, pp. 833-839, 1995.

[14] P. Trayhurn, "Hypoxia and adipocyte physiology: implications for adipose tissue dysfunction in obesity," Annual Review of Nutrition, vol. 34, pp. 207-236, 2014.

[15] C. E. Lowe, S. O'Rahilly, and J. J. Rochford, “Adipogenesis at a glance,” Journal of Cell Science, vol. 124, pp. 2681-2686, 2011.

[16] S. Mitsutake, T. Date, H. Yokota, M. Sugiura, T. Kohama, and Y. Igarashi, "Ceramide kinase deficiency improves diet-induced obesity and insulin resistance," FEBS Letters, vol. 586, pp. 1300-1305, 2012.

[17] J. Shen, I. Sakaida, K. Uchida, S. Terai, and K. Okita, "Leptin enhances TNF-alpha production via p38 and JNK MAPK in LPS-stimulated Kupffer cells," Life Sciences, vol. 77, pp. 1502-1515, 2005. 
[18] N. Iikuni, Q. L. Lam, L. Lu, G. Matarese, and A. L. Cava, "Leptin and inflammation," Current Immunology Reviews, vol. 4, pp. 70-79, 2008.

[19] V. Abella, M. Scotece, J. Conde et al., "Leptin in the interplay of inflammation, metabolism and immune system disorders," Nature Reviews Rheumatology, vol. 13, pp. 100-109, 2017.

[20] B. J. Pettus, A. Bielawska, S. Spiegel, P. Roddy, Y. A. Hannun, and C. E. Chalfant, "Ceramide kinase mediates cytokineand calcium ionophore-induced arachidonic acid release," The Journal of Biological Chemistry, vol. 278, pp. 3820638213, 2003.

[21] B. J. Pettus, A. Bielawska, P. Subramanian et al., "Ceramide 1-phosphate is a direct activator of cytosolic phospholipase A2," The Journal of Biological Chemistry, vol. 279, pp. 1132011326, 2004.

[22] J. A. Mietla, D. S. Wijesinghe, L. A. Hoeferlin et al., "Characterization of eicosanoid synthesis in a genetic ablation model of ceramide kinase," Journal of Lipid Research, vol. 54, pp. 1834-1847, 2013.

[23] B. M. Barth, S. J. Gustafson, J. L. Hankins et al., "Ceramide kinase regulates TNFalpha-stimulated NADPH oxidase activity and eicosanoid biosynthesis in neuroblastoma cells," Cellular Signalling, vol. 24, pp. 1126-1133, 2012.

[24] I. J. Lodhi and C. F. Semenkovich, "Peroxisomes: a nexus for lipid metabolism and cellular signaling," Cell Metabolism, vol. 19, pp. 380-392, 2014.

[25] K. M. Choi, Y. S. Lee, M. H. Choi et al., "Inverse relationship between adipocyte differentiation and ceramide level in 3T3L1 cells," Biological \& Pharmaceutical Bulletin, vol. 34, pp. 912-916, 2011.

[26] Z. Goktas, N. Moustaid-Moussa, C. L. Shen, M. Boylan, H. Mo, and S. Wang, "Effects of bariatric surgery on adipokineinduced inflammation and insulin resistance," Frontiers in Endocrinology (Lausanne), vol. 4, p. 69, 2013. 


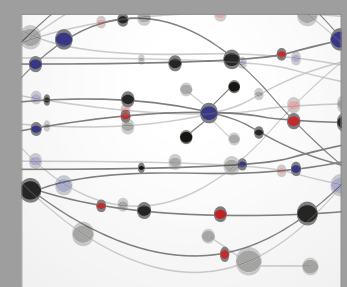

The Scientific World Journal
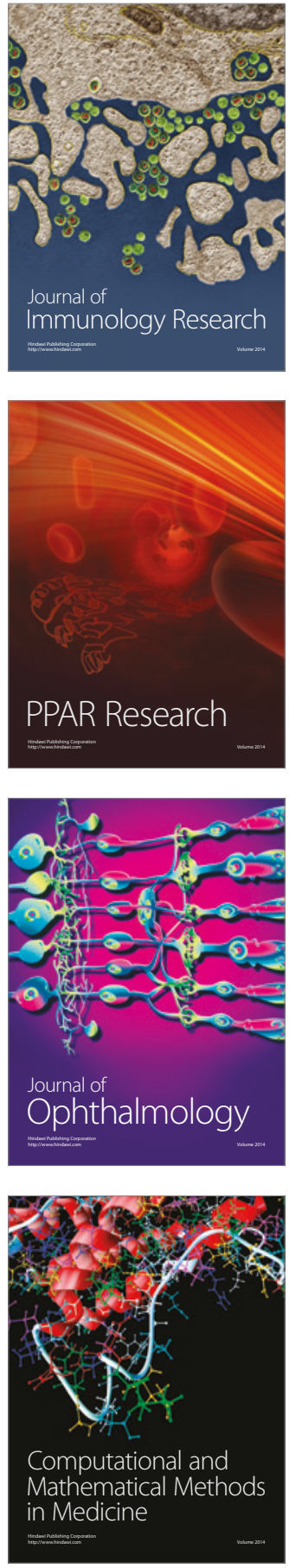

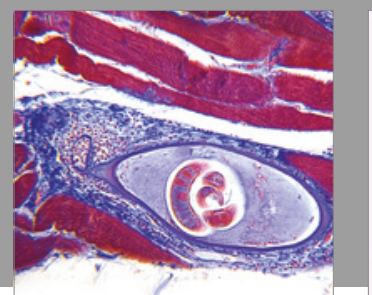

Gastroenterology Research and Practice
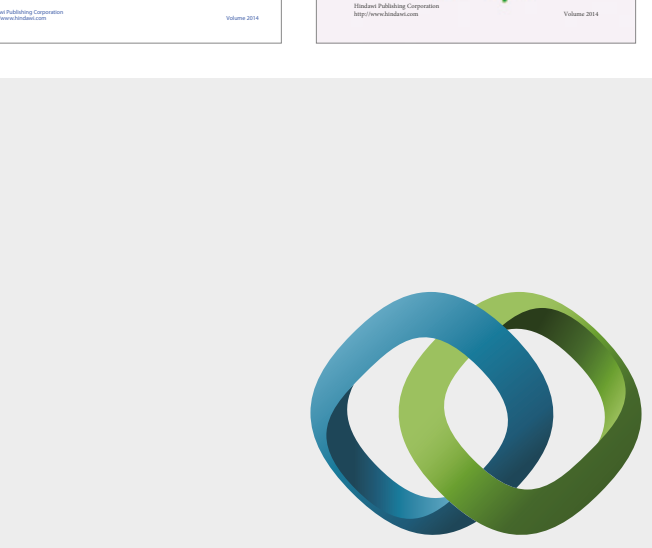

\section{Hindawi}

Submit your manuscripts at

https://www.hindawi.com
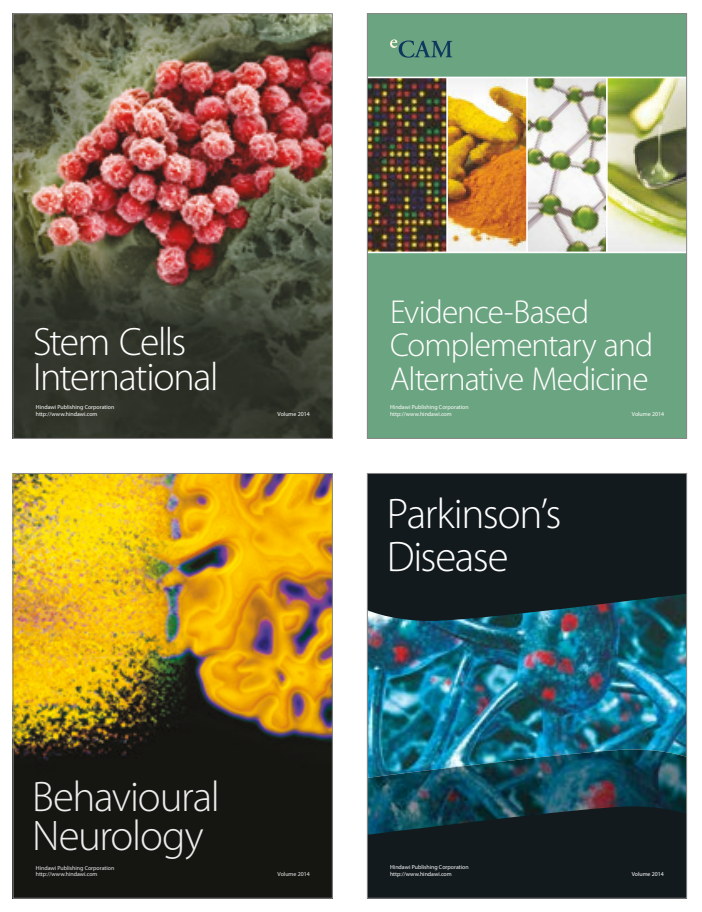
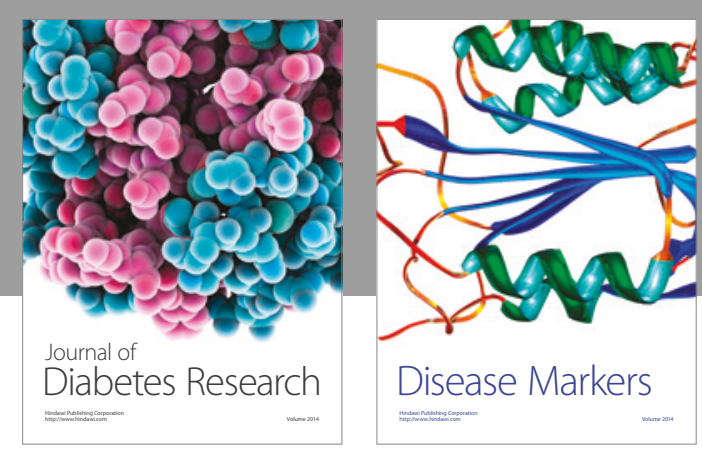

Disease Markers
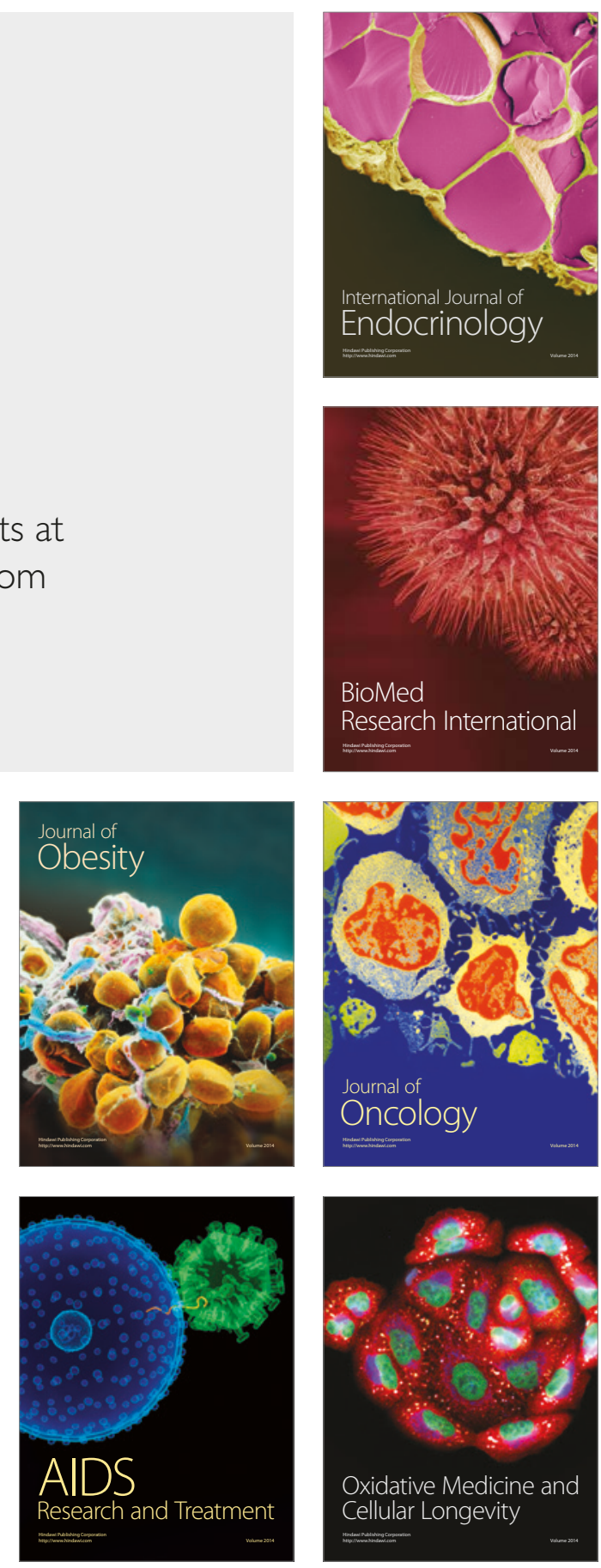